\title{
ALAT PENGUKUR DETAK JANTUNG MENGGUNAKAN PULSESENSOR BERBASIS ARDUINO UNO R3 YANG DIINTEGRASIKAN DENGAN BLUETOOTH
}

\author{
Galuh Wahyu Wohingati, Arkhan Subari \\ Program Studi Diploma III Teknik Elektro \\ Fakultas Teknik Universitas Diponegoro
}

\begin{abstract}
Galuh Wahyu Wohingati, Arkhan Subari, in paper pulse measuring tool using pulsesensor based on Arduino Uno R3 integrated with Bluetooth explain that emerging disease and claimed the lives of many people is often due to late treatment, when it should be in the modern era has many tools made to overcome this problem, medical devices can only be used by medical experts, and of course takes time and no small cost. as well as heart disease which sometimes can only be detected when it is advanced because of the lack of monitoring, both from people who are sick or from a doctor. Other factors that cause costs adalahkesibukan and not everyone can do medical check- ups regularly. Whereas By knowing the health condition of a person's heart rate will then be awake, do not need expensive care from a doctor, but could by changing lifestyle. Therefore it needs to be made a tool that can measure heart rate, showing whether or not the condition of the heart and of course, this tool can be used by everyone without kecuali.Dengan development of technology and the number of components on the market which can be accessed, Arduino Uno facilities in R3 can be used. Arduino is a physical computing platform that is open source means, Arduino can be developed by many people, not just programmers. But not just a development tool, Arduino is a combination of hardware, programming language and integrated development environment ( IDE ) that is advanced. Paired with a pulse sensor, a media reader analog heart rate is then converted into digital data that is in the readings, then integrated using serial bluetoothsecara so it can be displayed on your android smartphone and used repeatedly as needed measurements ..
\end{abstract}

Keywords : Arduino Uno R3, pulse sensor, Bluetooth

\section{PENDAHULUAN \\ Latar Belakang}

Dengan berkembangnya teknologi dalam kehidupan sehari-hari sudah sangat dirasakan oleh setiap orang.Perkembangan dalam bidang elektronika terjadi setiap waktu, mulai dari hal yang sangat bersifat sederhana.Bahkan perkembangan teknologi elektronika sudah dapat dikembangkan dalam bidang medis terutama dalam melakukan pengukuran. Antara lain bisa sebagai alat kontrol kesehatan, alat bantu penyembuhan dan lain-lain.

Untuk tahap awal pemeriksaan medis, biasanya dilakukan medical check up sebelum penyakit seseorang didiagnosa. Dari hasil medical check upakan diketahui apakah seseorang dalam kondisi sehat atau tidak. Pada umumnya medical check up yang dilakukan di rumah sakit pertama kali adalah detak jantung.Hal itu dilakukan karena jantung pada tubuh manusia merupakan organ utama, dimana fungsi kerja jantung mempengaruhi organ-organ penting manusia lainnya.

Berdasarkan pada kondisi tersebut kesehatan jantung manusia harus benar-benar diperhatikan.Hal yang dapat dilakukan secara dini adalah dengan melakukan pengecekan detak jantung secara rutin. Namun dalam melakukannya bisa dibilang gampanggampang susah. Jika kita menggunakan cara manual maka kita memerlukan perhitungan secara teliti dan sebelumnya telah mengerti prinsip dasar dalam melakukan pengukuran detak jantung.

Dari kondisi di atas timbul gagasan untuk merancangan dan membuat suatu alat yang dapat digunakan dengan mudah untuk membantu mengukur atau memantau detak jantung dengan bantuan sensor. Hasil dari pengukuran pulsesensorakan dikontrol melalui sebuah mikrokontrolerArduino Uno R3, kemudian akan dikirimkan melalui koneksi Bluetooth dan ditampilkan di smartphone dengan system operasi Android. Diharapkan alat ini dapat membantu mengetahui kondisi kesehatan dengan parameter diatas setidaknya untuk tahap awal pendeteksian.

\section{ARDUINO}

Arduino (Artanto, 2007) merupakan sebuah mikrokontroler dengan platform komputasi fisik (Physical Computing) open source sederhana. Yang dimaksud dengan platform komputasi fisik adalah sistem fisik yang interaktif dengan penggunaan software danhardware yang dapat mendeteksi dan merespon situasi dan kondisi yang ada didunia nyata. Dalam situs resminya, Arduino didefinisikan sebagai sebuah platform elektronik yang open source, berbasis pada software dan hardware yang fleksibel dan mudah digunakan, yang ditujukan untuk 
pengguna dan setiap orang yang tertarik dalam membuat objek atau lingkungan interaktif.

\section{ArduinoUnoR3}

ArduinoUnoR3 (Arduino, 2013) adalah papan mikrokontroler berdasarkan Atmega328. Arduino jenis ini memiliki 14 pin I/Odigital (dimana 6 pin dapat digunakan sebagai outputPWM), 6 input analog, $16 \mathrm{MHz}$ resonator keramik, port koneksi $U S B$ tipe $\mathrm{B}$, jack listrik, header ICSP, dan tombol RESET. Untuk tegangan inputArduinoUnoR3 didapat dari berbagai sumber diantaranya komputer melalui kabel USB, adaptor $A C-D C$ atau dengan baterai untuk menjalankan board ini.

ArduinoUno tidak menggunakan chip driver FTDI USB-to-serial seperti yang digunakan pada Arduino jenis lainnya. ArduinoUnoR3 telah menggunakan fitur Atmegal6U2, sedangkan untuk jenis Atmega8U2 digunakan hanya sampai versi $R 2$. Atmega seri ini diprogram sebagai konverter USB-toserial. Arduino UnoR3 memiliki resistor pada Atmega16U2 yang terhubung ke ground, sehingga lebih mudah untuk dimasukkan ke dalam mode $D F U$. Untuk spesifikasi lengkap pada Arduino UnoR3 dapat dilihat pada Tabel 1 .

Tabel 1. Spesifikasi Arduino Uno R3

\begin{tabular}{ll}
\hline Mikrokontroler & ATMega328 \\
Tegangan Operasi & $5 \mathrm{~V}$ \\
$\begin{array}{l}\text { Input voltage } \\
\text { (rekomendasi) }\end{array}$ & $7-12 \mathrm{~V}$ \\
Input voltage (batas) & $6-20 \mathrm{~V}$ \\
I/O pin digital & 14 (dengan 6 sebagai \\
Pin input analog & output PWM) \\
DC Lancar per I/O pin & $60 \mathrm{~mA}$ \\
DC Lanvar pin 3.3 V & $50 \mathrm{~mA}$ \\
Flash memory & $32 \mathrm{~KB}(0,5 \mathrm{~KB}$ untuk \\
SRAM & bootloader) \\
EEPROM & $2 \mathrm{~KB}$ \\
Kecepatan & $1 \mathrm{~KB}$ \\
\hline
\end{tabular}

ArduinoUnoR3 memiliki penambahan fitur baru. Diantaranya menambahkan pin SDA dan SCL yang dekat dengan pin AREF. Kemudian adanya pin RESET danpin IOREF yang memungkinkan shield untuk beradaptasi dengan tegangan yang disediakan dari board. Berikutnya yaitu adanya pin yang tidak terhubung, pin ini digunakan sebagai cadangan untuk tujuan perkembangan. Kemudian adanya pemindahan tombol RESET pada bagian samping Board. Yang terakhir adalah penggunaan Atmega 16U2 menggantikan Atmega. "Uno" memiliki arti "satu" dalam bahasa Italia dan pemberian nama tersebut sebagai tanda peluncuran Arduino 1.0. Uno dan versi
1.0 menjadi versi referensi dari Arduino untuk perkembangan selanjutnya. Uno merupakan Arduino yang terbaru dalam serangkaian USBBoardArduino, dan model referensi untuk platformArduino, sebagai perbandingan dengan versi sebelumnya.

ArduinoUno dapat diaktifkan melalui koneksi $U S B$ atau dengan catu daya eksternal. Sumber daya akan dipilih secara otomatis. Eksternal (non-USB) daya dapat berasal dari adaptor $A C-D C$ atau baterai. Pada input adaptor $A C-D C$ dapat dihubungkan dengan menancapkan sebuah konektor ukuran 2,1 mm dengan pusat-positif ke colokan yang telah tersedia pada board. Sedangkan penggunaan baterai dapat dimasukkan ke dalam header pin Gnd dan Vindari konektor daya.

ArduinoUnoR3 dapat beroperasi pada pasokan eksternal 6 sampai 20 volt. Meskipun ArduinoUnoR3 dapat diberi tegangan kurang dari $7 \mathrm{~V}$, namun hal ini mengakibatkan ketidakstabilan. Kemudian ketika menggunakan tegangan lebih dari $12 \mathrm{~V}$, regulator tegangan akan panas dan merusak papan. Tegangan yang disarankan adalah 7 sampai 12 volt.

\section{Arduino IDE (Integrated Development Environment).}

ArduinoIDE (Artanto,2007) adalah sebuah sistem operasi yang digunakan secara khusus untuk perancangan program Arduino, meskipun sebenarnya Arduino bisa digunakan di sistem operasi yang lain . Langkah awal penggunaan ARDUINOIDE adalah dengan melakukan istalasi terlebih dahulu.

Untuk menjalankan softwareIDE ini, layaknya menjalankan sebuah aplikasi pada umumnya.Seperti halnya bahwa kelebihan Arduino adalah pada penggunaan IDE-nya yang mudah karena kesederhanaannya.Program di softwareArduino sering disebut sebagai sketch.

\section{Instruksi ArduinoIDE}

Ada tiga bagian utama dalam bahasa pemrograman Arduino (Artanto,2007), yaitu struktur, Variabel, Fungsi. Bagian struktur Arduino ini meliputi kerangka program, sintaks program, kontrol aliran program, dan operator.

\section{Kerangka program}

Kerangka program Arduino sangat sederhana, yaitu terdiri dari dua blok. Blok pertama adalah void $\operatorname{setup}()$, dan blok kedua adalah void loop().

\section{Sintaks program}

Baik blok void setup(), void loop() maupun blok functionharus diberi tanda kurung kurawal buka "\{“ sebagai tanda awal program di blok itu dan kurung kurawal tutup " $\}$ " sebagai tanda akhir program. 
Tanda kurung kurawal buka dan kurung kurawal tutup tersebut juga digunakan pada blok kontrol program, seperti if, if-else, for-loop, whileloop dando-while-loop.

Untuk menandai akhir sebuah baris kode program digunakan tanda titik koma ";",

\section{Kontrol Aliran Program}

Kontrol aliran program ini meliputi instruksiinstruksi yang digunakan untuk membuat percabangan dan perulangan. Instruksi percabangan diantaranya adalah if, if-else, switch case, break, continue, return dangoto. Sedangkan instruksi perulangan diantaranya adalah for-loop, while-loop, do-while-loop.

\section{SENSOR}

Sensor (Septiawan, 2013) adalah alat untuk mendeteksi/mengukur sesuatu, yang digunakan untuk mengubah variasi mekanis, magnetis, panas, sinar dan kimia menjadi tegangan dan arus listrik. Dalam lingkungan sistem pengendali dan robotika, sensor memberikan kesamaan yang menyerupai mata, pendengaran, hidung, lidah yang kemudian akan diolah oleh kontroler sebagai otaknya .

\section{Pulsesensor}

Pulsesensor (Gitman, 2013) adalah sebuah sensor denyut jantung yang dirancang untuk Arduino.Sensor ini dapat digunakan untuk mempermudah penggabungan antara pengukuran detak jantung dengan aplikasi data ke dalam pengembangannya.Pulsesensor mencakup sebuah aplikasi monitoring yang bersifat open source.

Bagian depan sensor memiliki sisi cantik dengan logo hati. Sisi ini yang membuat kontak dengan kulit. Pada sisi ini dapat dilihat sebuah lubang bulat kecil yang mana bersinar $L E D$ dari belakang dan ada juga persegi kecil tepat di bawah LED. Persegi kecil itu adalah sebuah sensor cahaya, persis seperti yang digunakan dalam ponsel, tablet, dan laptop, untuk menyesuaikan kecerahan layar dalam kondisi cahaya yang berbeda.

Pada Pulsesensor digunakan LED berwarna hijau, karena sensor cahaya yang digunakan yaitu APDS-9008 memiliki puncak sensitivitas sebesar $565 \mathrm{~nm}$. Dalam hal ini $L E D$ hijau memiliki panjang gelombang 495-570 $\mathrm{nm}$ sehingga sesuai dengan kebutuhan sensor tersebut.

\section{BLUETOOTH}

Bluetooth (Nugroho, 2013) adalah sebuah teknologi nirkabel dengan menggunakan media gelombang radio yang bekerja pada frekuensi 2.4 GHz. Bluetooth menggunakan sistem Frequency Hopping Spread Spectrum (FHSS) yang mempunyai kecepatan maksimum 1 Mbps. Bluetooth terbagi menjadi 2 kelas yaitu kelas 1 yang mempunyai jangkauan maksimum +- $100 \mathrm{~m}$ dan kelas 2 yang mempunyai jangkauan maksimum $15 \mathrm{~m}$. Pada awalnya teknologi bluetooth dipromosikan untuk penggunaan LAN. Namun, mengingat jangkauan maksimum yang tidak terlalu luas, bluetooth kemudian dipromosikan untuk penggunaan dalam personal area network (PAN).

\section{BluetoothHC-05}

$H C$ merupakan produk Bluetooth seri yang terdiri dari modul Bluetooth interface serial dan adapter (Bluetooth HC, 2013). Modul Bluetoothserial digunakan untuk mengkonversi port serialBluetooth. Modul ini memiliki dua mode: master dan slave. Perangkat BluetoothHC yang dinamai dengan angka genap didefinisikan untuk menjadi master atau slave saja ketika keluar dari pabrik dan tidak dapat diubah ke mode lainnya. Tapi untuk perangkat dinamai angka ganjil, pengguna dapat mengatur mode kerja (master atau slave) dari perangkat dengan perintah $A T$.

\section{KOMUNIKASI SERIAL}

Komunikasi serial (Budiharjo, 2007) merupakan komunikasi data dengan pengiriman data secara satu per satu pada waktu tertentu. Sehingga komunikasi data serial hanya menggunakan dua kabel yaitu kabel data untuk pengiriman yang disebut transmit ( $T X$ ) dan kabel data untuk penerimaan yang disebut receive ( $R X)$. Kelebihan dari komunikasi serial adalah jarak pengiriman dan penerimaan dapat dilakukan dalam jarak yang cukup jauh dibandingkan dengan komunikasi parallel tetapi kekurangannya kecepatannya lebih lambat dibandingkan komunikasi parallel.

\section{JANTUNG}

Jantung (Pearce, 2007) merupakan pusat dari sistem peredaran darah manusia dan hewan lainnya.Jantung pada manusia memiliki 4 ruangan.Ruangan bagian atas merupakan "serambi jantung" sedangkan dua ruang dibawahnya disebut sebagai "bilik jantung". Sekat yang menghubungkan antara bilik dan serambi jantung bagian kanan disebut valva bikuspidalis (valva : katup, $b i$ : dua).

\section{Detak Jantung}

Denyut merupakan pemeriksaan pada pembuluh nadi atau arteri.Ukuran kecepatannya diukur pada beberapa titik denyut misalnya denyut arteri radialis pada pergelangan tangan, arteri brachialis pada lengan atas, arteri karotis pada leher, arteri poplitea pada belakang lutut, arteri dorsalis pedis atau arteri tibialis posterior pada kaki. 
Jantung dapat dijadikan sebuah indikator kesehatan, hal ini dapat diamati dengan terjadinya peningkatan denyut nadi pada saat beristirahat. Waktu yang tepat untuk mengecek denyut nadi adalah saat kita bangun pagi dan sebelum melakukan aktivitas apapun. Pada saat itu kita masih relaks dan tubuh masih terbebas dari zat-zat pengganggu seperti nikotin dan kafein. Kita dapat mengecek sendiri dengan merasakan denyut nadi di bagian tubuh tertentu. (Denyut Nadi Normal, 2013)

\section{Pengukuran detak jantung}

Dalam pengukuran detak jantung ini berguna untuk mengetahui kondisi tubuh dengan mengacu pada jenis kelamin dan umur.

Tabel 2. Detak jantung laki-laki

\begin{tabular}{|l|c|c|c|c|c|c|}
\hline \multicolumn{7}{|c|}{ DETAK JANTUNG ISTIRAHAT LAKI-LAKI } \\
KONDISI UMUR & $18-25$ & $26-35$ & $36-45$ & $46-55$ & $56-65$ & $65+$ \\
\hline SANGAT BAIKSEKALI & $49-55$ & $49-54$ & $50-56$ & $50-57$ & $51-56$ & $50-55$ \\
\hline SANGAT BAIK & $56-61$ & $55-61$ & $57-62$ & $58-63$ & $57-61$ & $56-61$ \\
\hline BAIK & $62-85$ & $62-85$ & $63-86$ & $64-87$ & $62-87$ & $62-85$ \\
\hline LEBIH DARI CUKUP & $86-89$ & $86-90$ & $87-90$ & $88-91$ & $88-91$ & $86-89$ \\
\hline CUKUP & $90-93$ & $91-94$ & $91-95$ & $92-96$ & $92-95$ & $90-93$ \\
\hline KURANG & $94-101$ & $95-101$ & $96-102$ & $97-103$ & $96-101$ & $94-99$ \\
\hline BURUK & $102+$ & $102+$ & $103+$ & $104+$ & $102+$ & $100+$ \\
\hline
\end{tabular}

Tabel 3. Detak jantung perempuan

\begin{tabular}{|l|c|c|c|c|c|c|}
\hline \multicolumn{7}{|c|}{ DETAK JANTUNG ISTIRAHAT PEREMPUAN } \\
\hline KONDISI UMUR & $\mathbf{1 8 - 2 5}$ & $\mathbf{2 6 - 3 5}$ & $\mathbf{3 6 - 4 5}$ & $\mathbf{4 6 - 5 5}$ & $\mathbf{5 6 - 6 5}$ & $\mathbf{6 5 +}$ \\
\hline SANGAT BAIKSEKALI & $54-60$ & $54-59$ & $54-59$ & $54-60$ & $54-65$ & $54-59$ \\
\hline SANGAT BAIK & $61-65$ & $60-64$ & $60-64$ & $61-65$ & $60-64$ & $60-64$ \\
\hline BAIK & $66-89$ & $65-88$ & $65-89$ & $66-89$ & $65-88$ & $65-88$ \\
\hline LEBIH DARI CUKUP & $90-93$ & $89-92$ & $90-93$ & $90-93$ & $89-93$ & $89-92$ \\
\hline CUKUP & $94-98$ & $93-96$ & $94-98$ & $94-97$ & $94-97$ & $93-96$ \\
\hline KURANG & $99-104$ & $97-102$ & $99-104$ & $98-103$ & $98-103$ & $97-104$ \\
\hline BURUK & $105+$ & $103+$ & $105+$ & $104+$ & $104+$ & $104+$ \\
\hline
\end{tabular}

Tabel 2. menjelaskan bagaimana kriteria detak jantung seorang laki-laki berdasarkan umur. Sedangkan dalam table 3 adalah tabel kondisi seorang wanita. (Top End Sport Resting Heart Rate Table, 2013)

\section{BLOK DIAGRAM}

Blok diagram dari alat pengukur detak jantung menggunakan pulsesnsor berbasis ArduinoUnoR3 yang diintegrasikan dengan Bluetooth dapat dilihat pada gambar 1 .

Dari blok diagram tersebut dapat dilihat beberapa bagian utama diantaranya:

- ArduinoUnoR3

- Baterai 9V

- PulseSensor

- Bluetooth

- SmartphoneAndroid

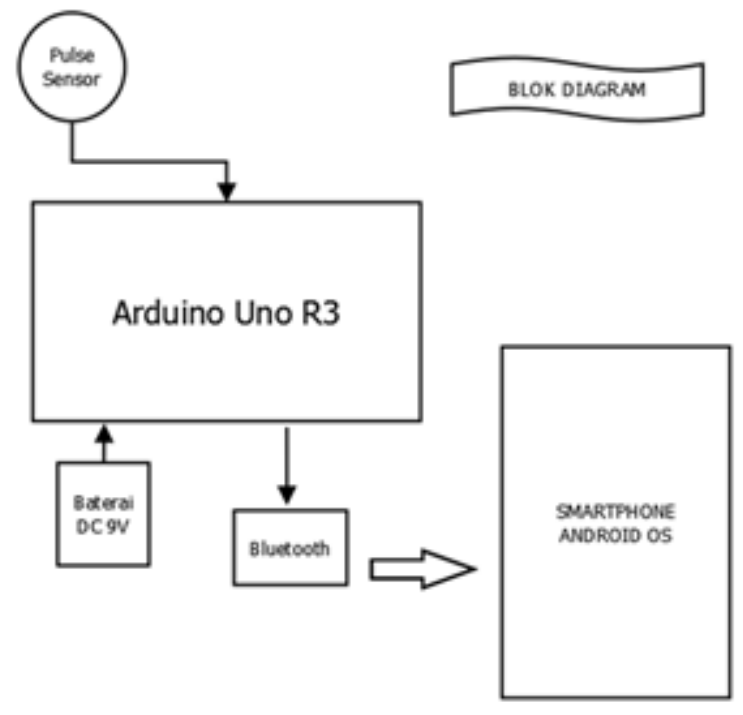

Gambar 1. Blok diagram alat

\section{PRINSIP KERJA SISTEM DIAGRAM BLOK}

Pada alat ini ArduinoUnoR3 merupakan komponen utama. Arduino berperan sebagai otak dalam alat ini. ArduinoUnoR3 diaktifkan melalui sumber tegangan dari baterai $D C 9 \mathrm{~V}$. Dari sumber tegangan tersebut, Arduino akan mensuplai tegangan untuk pulsesnsor dan bluetooth. Pulsesnsor akan diberi tegangan oleh ArduinoUnoR3 sebesar 5V dan bluetooth mendapatkan tegangan sebesar $3,3 \mathrm{~V}$. Ketika semua komponen telah aktif, maka alat akan mulai bekerja.

Pulsesensor akan mendeteksi detak jantung pada manusia dan kemudian data itu diproses oleh ArduinoUnoR3. Ketika proses perhitungan detak jantung telah selesai, data kemudian dikomunikasikan secara serial dan dikirimkan melalui Bluetooth menuju SmartphoneAndroid.

\section{ArduinoUnoR3}

ArduinoUNOR3 berfungsi sebagai modul kontroler utama pada sistem yang menggunakan mikrokontroler AVRATmega328. Gambar skematik rangkaian ada alat ini dapat dilihat pada gambar 3.2

ArduinoUnoR3 akan mengontrol kinerja Pulsesnsor dan BluetoothHC-05. Sebagai konfigurasi pinnya yaitu:

- Pin power Vin

Pin ini digunakan sebagai suplay tegangan. Pin ini terhubung oleh Baterai $D C 9 \mathrm{~V}$.

- $\quad$ Pin power $5 \mathrm{~V}$

Pin power $5 \mathrm{~V}$ merupakan pin output yang mensuplay tegangan sebesar $5 \mathrm{~V}$. Pin ini untuk membangkitkan pulsesnsor. 


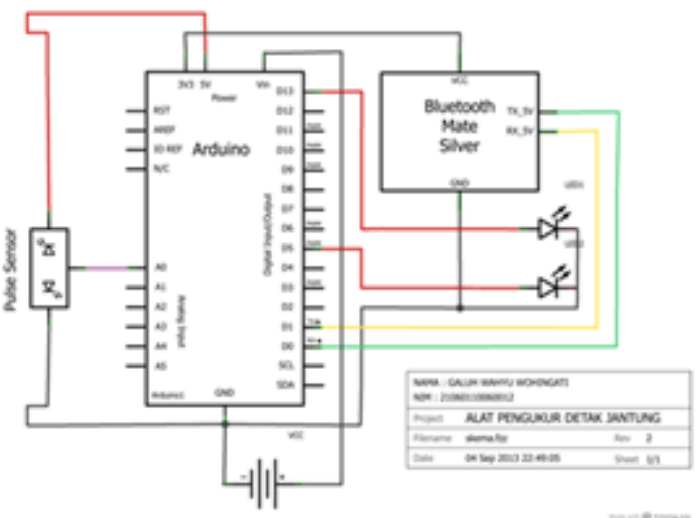

Gambar 2. Gambar rangkaian

- $\quad$ Pin power $3.3 \mathrm{~V}$

Pin power $3,3 \mathrm{~V}$ merupakan pin output yang mensuplay tegangan sebesar 3,3 V. Pin ini untuk mengaktifkan BluetoothHC-05.

- Pin powerGND

Pin powerGND merupakan pin Ground yang terhubung dengan ground pada Baterai $9 \mathrm{~V}$, BluetoothHC-05, dan Pulsesnsor.

- $\quad$ Pin Analog 0 (A0)

Input Analog pada pin A0 merupakan pin yang mendapatkan input dari pulsesnsor.

- $\quad$ Pin Digital $0(R X)$

Pin Digital 0 memiliki fungsi sebagai receiver yang menghubungkan dengan pin transceiver pada BluetoothHC-05.

- $\quad$ Pin Digital $1(T X)$

Pin Digital 0 memiliki fungsi sebagai transceiver yang terhubung dengan pin receiver pada BluetoothHC-05.

\section{CARA KERJA PROGRAM}

Gambar 3 menunjukan flowchart program "Alat Pengukur Detak Jantung Menggunakan Pulsesnsor Berbasis ArduinoUnoR3 Yang Diintegrasikan Dengan Bluetooth".

Untuk penjelasan proses secara lengkap dapat dilihat penjabaran proses beserta penjelasan listing programnya.

\section{PEMBUATAN ALAT}

Dalam pembuatan alat "Alat Pengukur Detak Jantung Menggunakan Pulsesensor Berbasis ArduinoUno $R 3$ yang Diintegrasikan dengan Bluetooth" melalui beberapa tahap, diantaranya:

- Bagian Hardware, meliputi perencanaan alat, pembuatan tempat, perancangan rangkaian, pemasangan rangkaian dan perakitan alat.

- Bagian Software, perencanaan sistem dan flashing program.

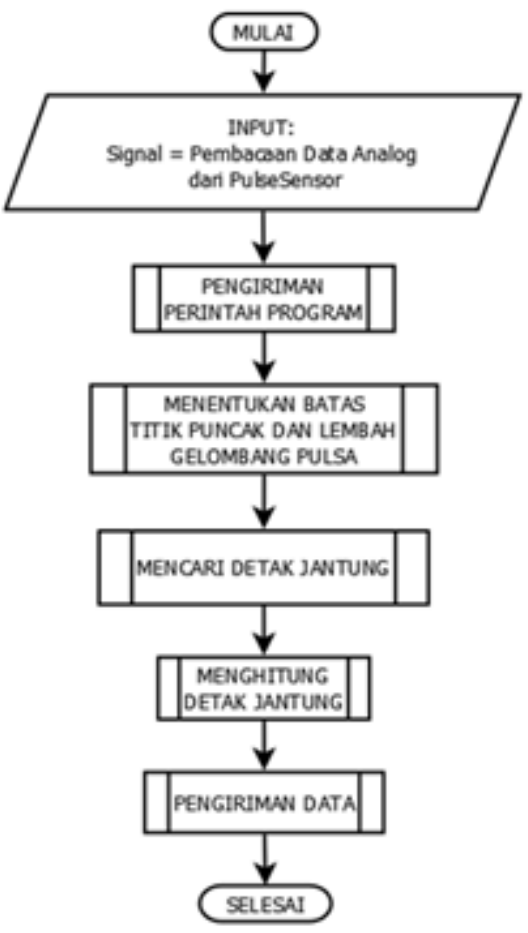

Gambar 3. Flowchart program

\section{PENGUJIAN DAN PENGUKURAN \\ Cara Penggunaan Alat}

Sebelum melakukan pengujian terlebuh dahulu perlu diketahui cara penggunaan alat. Untuk menggunakan hal pertama yang perlu diperhatikan adalah baterai sebagai $9 \mathrm{~V}$. Kemudian nyalakan alat dengan cara menggeser saklar pada posisiON. Kemudian tempelkanujung jari pada sensor pendeteksi detak jantung (pulsesensor) seperti terlihat pada gambar 4 .

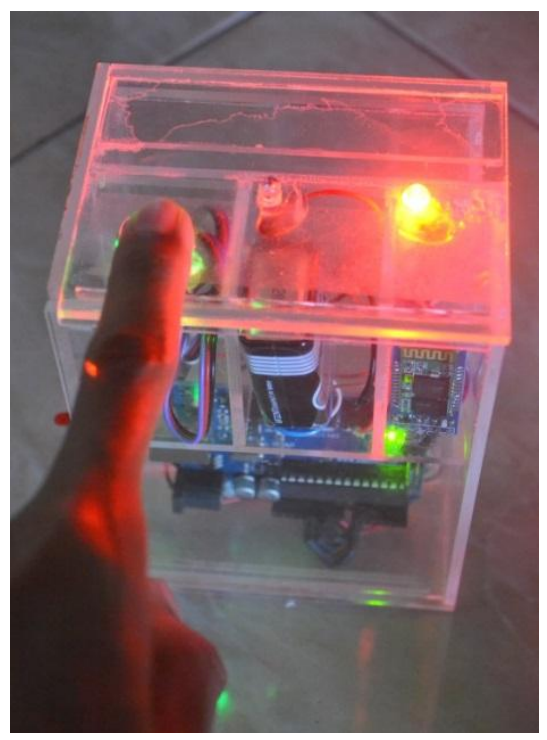


Gambar 4. Penggunaan Alat

Pertahankan posisi jari hingga didapatkan kondisi yang stabil. Untuk mengetahui kondisi tersebut dapat dilihat pada lampu indikator alat akan menyala dan meredup sesuai datak jantung yang diukur.

Kemudian untuk penggunaan aplikasi. Saat pertama kali aplikasi dibuka, akan dihadapkan dengan 3 pilihan menu. Diantaranya yaitu panduan aplikasi, perhitungan detak jantung, dan tentang aplikasi.Untuk tampilan aplikasinya dapat dilihat pada gambar 5 .

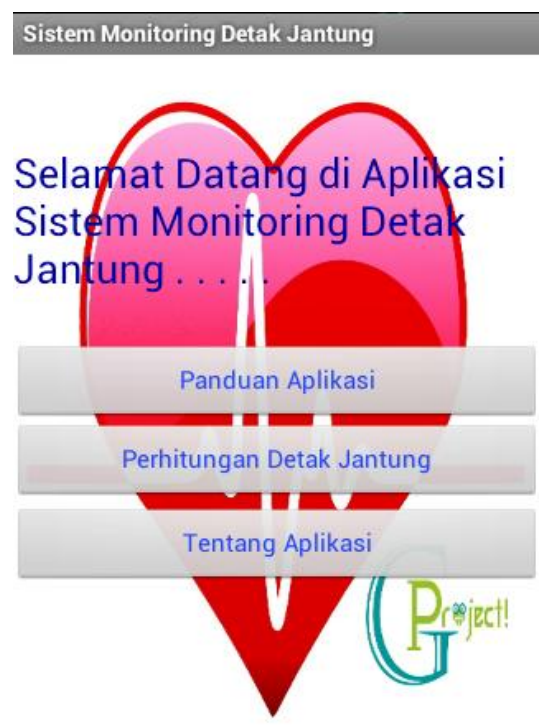

Gambar 5. Tampilan Awal

Dari tampilan awal tadi ketika selanjutnya kita pilih panduan aplikasi maka akan menampilkan tentang panduan dalam penggunaan aplikasi. Ketika halaman panduan aplikasi telah ditampilkan, kita juga akan diberikan pilihan kembali untuk melanjutkan ke halaman "Perhitungan Detak Jantung" atau menekan tombol back/kembali pada smartphone untuk kembali ke menu tampilan awal.

\section{Pengujian}

Pengujian bertujuan mengetahui kondisi perbandingan dari alat yang dibuat dengan kondisi nyata. Dalam pengujian ini memiliki 3 perbandingan perhitungan.

Perhitungan secara manual, yaitu perhitungan detak jantung melalui arteri radalis yang berada pada pergelangan tangan. Dilakukan selama 1 menit karena satuan yang digunakan berupa Bite Per Minute (BPM).

Perhitungan melalui Indikator Alat, yaitu melihat nyala dan redupnya indikator ketika kita melakukan pengukuran. Dalam pengukuran ini, indikator led menyala dan meredup sesuai detak jantung manual. Jadi dapat dipastikan bahwa jumlah yang didapatkan nantinya antara cara manual dengan indikator adalah sama.

Tabel 4. Hasil pengujian

\begin{tabular}{|c|c|c|c|c|c|}
\hline \multirow{2}{*}{ SAMPEI } & \multicolumn{2}{|c|}{ PERHITUNGAN DETAK IANTUNG } & \multicolumn{2}{c|}{ SEUSIH PENGUKURAN } \\
\cline { 2 - 6 } & $\begin{array}{c}\text { SECARA } \\
\text { MANUAL }\end{array}$ & $\begin{array}{c}\text { INDIKATOR } \\
\text { ALAT }\end{array}$ & $\begin{array}{c}\text { DATA } \\
\text { APUKASI }\end{array}$ & JUMLAH & PRESENTASE \\
\hline $\mathbf{1}$ & 66 & 66 & 66 & 0 & $0 \%$ \\
\hline $\mathbf{2}$ & 69 & 69 & 70 & 1 & $1.45 \%$ \\
\hline 3 & 68 & 68 & 68 & 0 & $0 \%$ \\
\hline 4 & 71 & 71 & 71 & 0 & $0 \%$ \\
\hline 5 & 74 & 74 & 73 & 1 & $1.35 \%$ \\
\hline $\mathbf{6}$ & 62 & 62 & 62 & 0 & $0 \%$ \\
\hline 7 & 63 & 63 & 63 & 0 & $0 \%$ \\
\hline 8 & 70 & 70 & 70 & 0 & $0 \%$ \\
\hline 9 & 81 & 81 & 81 & 0 & $0 \%$ \\
\hline 10 & 64 & 64 & 64 & 0 & $0 \%$ \\
\hline
\end{tabular}

\section{PENGUKURAN}

Pengukuran disini adalah menggunakan alat kepada beberapa orang untuk mengetahui kinerja alat sesungguhnya.Pengukuran dilakukan pada 10 orang dimana diantaranya 5 orang laki-laki dan 5 orang perempuan dengan variasi umur yang berbeda.

Dalam pengukuran tidak dilakukan dengan observasi pada penderita suatu penyakit.Tujuan dilakukannya pengukuran hanya untuk mengetahui aplikasi system monitoring detak jantung dapat berjalan dengan baik. Selanjutnya untuk hasil pengukuran yang telah dilakukan dapat dilihat pada tabel 5 .

Tabel 5. Hasil pengukuran

\begin{tabular}{|c|l|c|l|c|l|}
\hline NO & \multicolumn{1}{|c|}{ NAMA } & $\begin{array}{c}\text { UMMUR } \\
\text { (Tahun) }\end{array}$ & $\begin{array}{c}\text { JENIS } \\
\text { KELAMIN }\end{array}$ & $\begin{array}{c}\text { JUMLAH } \\
\text { DETAK } \\
\text { (BPM) }\end{array}$ & KONDESI \\
\hline 1 & WISNU RESWARA & 2 & LAKI-LAKI & 80 & BAIK \\
\hline 2 & FIRMANSYAH & 13 & LAKI-LAKI & 99 & BURUK \\
\hline 3 & M. TAUFIQ & 21 & LAKI-LAKI & 69 & BAIK \\
\hline 4 & SURYADI PUDYA. & 21 & LAKI-LAKI & 66 & BAIK \\
\hline 5 & SUPADI WS & 52 & LAKI-LAKI & 70 & BAIK \\
\hline 6 & ASTRI AMAYA & 3 & PEREMPUAN & 75 & BAIK \\
\hline 7 & DIAHARUM & 5 & PEREMPUAN & 72 & BAIK \\
\hline 8 & GALUHWWAMU & 21 & PEREMPUAN & 67 & BAIK \\
\hline 9 & WAHMU TUTK & 28 & PEREMPUAN & 94 & CUKUP \\
\hline 10 & WAGINAH & 65 & PEREMPUAN & 65 & BAIK \\
\hline
\end{tabular}

\section{KESIMPULAN}

Kesimpulan yang dapat diambil dalam penelitian ini adalah :

- Kinerja Pulsesensor (Brand Sparkfun) memiliki tingkat sensitivitas dan pembacaan yang sedikit lambat.

- Penggunaan Bluetooth seri HC-05 memiliki tingkat kecepatan integrasi yang cepat dengan jarak yang tergolong jauh sehingga sesuai dengan kebutuhan.

- Arduino Uno $R 3$ sebagai $A D C$ dapat dengan tepat melakukan proses perubahan data analog 
menjadi digital dan melakukan perintah pengiriman dengan sangat baik.

- Dalam pengukuran yang dilakukan pada 10 orang yaitu 4 orang dengan umur dibawah 13 tahun, 3 orang laki diatas 18 tahun dan 3 orang perempuan diatas 18 tahun.

○ Pada pengukuran 4 orang dengan umur dibawah 18 Tahun tidak terjadi kesalahan. Penunjukan kondisi pada aplikasi dengan database tabel Detak Jantung Umur dibawah 18 Tahun memiliki hasil yang sama.

- Pada pengukuran 3 orang laki-laki diatas 18 Tahun tidak terjadi kesalahan. Penunjukan kondisi pada aplikasi dengan database tabel Detak Jantung Istirahat Laki-laki memiliki hasil yang sama.

- Pada pengukuran 3 orang perempuan diatas 18 Tahun tidak terjadi kesalahan. Penunjukan kondisi pada aplikasi dengan database tabel Detak Jantung Istirahat Perempuan memiliki hasil yang sama.
DAFTAR PUSTAKA

1. Arduino, 2013, Arduino Uno R3. http://www. http://arduino.cc/en/Main/Arduino BoardUno/.

2. Artanto, Dian. 2007. Interaksi Arduino dan Labview . Jakarta : PT Elex Media Komputindo.

3. Anonimous, 2013, Denyut Nadi Normal. http://www.apotas.com/7167/denyut-nadinormal/.

4. Anonimous, 2013, Top End Sport. Resting Heart Rate Table. http://www.topendsports.com/testing/heart-rateresting-chart.htm/.

5. Bluetooth HC. 2013, Bluetooth HC-05 Serial Module . http://hcmodule.com/2013/06/19/ using-the-hc-06-bluetooth-module/.

6. Budiharjo,Widodo. 2007. Panduan Praktikum Mikrokontroler Atmega16. Jakarta: PT. Elex Media Komputindo.

7. Gitman, Yuri. 2013, Pulse Sensor. http://www.pulsesensor.com/.

8. Masagung Nugroho, 2013, Teknologi Bluetooth, http://digilib.ittelkom.ac.id/.

9. Pearce, Evelyn Pearce, "Anatomy and Physiology for Paramedics", Gramedia, 2007.

10. Septiawan, Faris Septiawan. 2013. Sensor. http://farisseptiawan.blogspot.com/2010/03/peng ertian-sensor.html/ 